\title{
DIAGNÓSTICO DA ARBORIZAÇÃO URBANA DO MUNICÍPIO DE OURO VERDE DO OESTE, PARANÁ
}

\author{
DIAGNOSIS OF URBAN FORESTATION IN THE CITY OF \\ OURO VERDE DO OESTE, PARANÁ
}

\author{
Jéssica Manfrin ${ }^{1}$, Mayara Andria da Silva Escher², Guilherme Miola de Castro ${ }^{3}$, Valdemir Aleixo ${ }^{4}$, \\ Andréia Inês Petry ${ }^{5}$, Thyago Bueno ${ }^{6}$
}

\section{RESUMO}

Antigamente a vegetação urbana era utilizada apenas para embelezamento das cidades, porém na atualidade, devido às questões ambientais e melhoria na qualidade de vida proporcionada pela vegetação, a mesma é tida como necessária para o equilíbrio entre a vida urbana e o meio ambiente, observando, portanto, a necessidade de toda e qualquer cidade possuir um plano de gestão destinado à arborização urbana. $O$ presente trabalho teve como objetivo analisar os aspectos qualitativos $\mathrm{e}$ quantitativos da arborização urbana no município de Ouro Verde do Oeste/PR. Foram catalogadas 1249 árvores, dentre elas, a espécie Caesalpinia peltophoroides foi a de maior ocorrência, com 614 indivíduos, seguido pelo Ligustrum lucidum com 107 indivíduos. Mais de $50 \%$ das espécies da arborização foi classificada como nativa e apenas 30 indivíduos não foram identificados. No cálculo de índice de área verde observou se um déficit de unidades arbóreas, entretanto quando comparado com outros munícipios Ouro Verde do Oeste apresenta melhores resultados tendo aproximadamente $6,01 \mathrm{~m}^{2}$ hab $^{-1}$. Dessa forma, este estudo poderá auxiliar o poder público municipal na elaboração de um plano de arborização e readequação das condições da arborização, o que em suma estará beneficiando toda população ouroverdense.

Palavras-chave: Índice de Área Verde; Espécies Arbóreas; Planejamento Arbóreo; Qualidade de Vida.

\begin{abstract}
In the past urban vegetation was only used to embellish cities, but nowadays due to environmental issues and improvement in the quality of life provided by vegetation, it is considered necessary for the balance between urban life and the environment, then observing the need for any city to have a management plan for urban afforestation. The present study had as objective to analyze the qualitative and quantitative aspects of the urban afforestation in the municipality of Ouro Verde do Oeste/PR. A total of 1249 trees were cataloged, being Caesalpinia peltophoroides the one that stood out more with 614 individuals followed by Ligustrum Lucidum with 107 individuals. More than $50 \%$ of the species of afforestation was classified as native and only 30 individuals were not identified. In the calculation of green area index, it was observed a deficit of tree units, however when compared to other municipalities, Ouro Verde do Oeste presents better results having approximately $6.01 \mathrm{~m}^{2} \mathrm{hab}^{-1}$. In this way, this study could help the municipal government in the elaboration of an afforestation plan and readjustment of the conditions of the afforestation, which in short will be benefiting all population of the municipality.
\end{abstract}

Keywords: Green area index; Arboreal species; Arboreal planning; Life quality.

Recebido em 15.03.2018 e aceito em 16.01.2019

1 Engenheira Ambiental. Mestre. Formada pela Pontifícia Universidade Católica do Paraná (PUC-PR). Toledo/PR. Email:jessicamanfrinn@gmail.com

2 Engenheira Ambiental. Especialista. Formada pela PUC-PR. Corbélia/PR. Email: mayaraandria@hotmail.com

3 Engenheiro Ambiental. Mestre. Formado pela PUC-PR. Toledo/PR. Email: ecoraambiental@gmail.com

4 Biólogo. Doutor. Professor Titular da Pontifícia Universidade Católica do Paraná. Email: valdemir.aleixo@pucpr.br 5 Engenheira Ambiental. Especialista. Formada pela PUC-PR. Corbélia/PR. Email: andreiapetry1992@hotmail.com

6 Engenheiro Ambiental. Formado pela PUC-PR. Toledo/PR. Email: thyago_bueno@hotmail.com 


\section{INTRODUÇÃO}

O processo acelerado de urbanização, ocorrido no Brasil a partir da década de 1970, e a falta de aplicação ou inexistência de políticas públicas eficazes, trouxeram consigo benefícios, entretanto, eles também foram responsáveis por inúmeros desordenamentos. A construção e o desenvolvimento de cidades somado ao crescimento da densidade populacional foram responsáveis por alterações consideráveis na qualidade e características primárias do solo, da água, do ar, dos ecossistemas e da devastação da vegetação nativa (BARGOS; MATIAS, 2012).

Um dos principais fatores que contribuem para o aumento de áreas urbanas é o crescimento populacional, e, segundo dados apresentados pela Organização das Nações Unidas - ONU (2015), a população urbana a nível mundial tem crescido rapidamente. Os dados mostram que em 1950 , apenas $30 \%$ da população mundial era considerada urbana, atualmente a porcentagem de pessoas vivendo em regiões urbanas é de $54 \%$ e as previsões indicam que no ano de 2050 66\% da população mundial viverá em cidades.

Entretanto, o processo de urbanização contribuiu drasticamente para que espaços destinados a este fim fossem destinados a outros, como por exemplo, habitação e parques industriais. Diante desta situação intensificou-se uma alternativa, a arborização de vias públicas, como, canteiros centrais, passeios públicos e faixas de acompanhamento viário. De acordo com McPherson et al. (2011), os benefícios deste tipo de arborização também estão atrelados à qualidade de vida da população. Porém, este tipo de arborização deve apresentar um bom planejamento independente do porte da cidade ou do número de habitantes, sendo indispensável para prevenir possíveis problemas futuros. Entre os benefícios oriundos da arborização urbana destaca-se que as árvores podem reduzir a incidência da luz em mais de $90 \%$, diminuindo a temperatura e a luz direta sobre quem caminha ou se exercita sob elas, influenciando positivamente no conforto térmico das cidades (MARTINI; BIONDI, 2015)

É importante ressaltar que a qualidade de vida urbana está diretamente atrelada a vários fatores que estão reunidos na infraestrutura, no desenvolvimento econômico e social, e àqueles ligados à questão ambiental. Entretanto, com o passar do tempo o ambiente urbano se torna cada vez mais deteriorado devido à elevada produção de resíduos que polui o solo e a água, o alto índice de construções, que muitas vezes geram espaços com pouca ou nenhuma espécie arbórea, afetando assim, cada vez mais a qualidade de vida das pessoas (PORTNEY, 2013).

De acordo com Kramer e Krupek (2012), toda cidade deve investir em programas de estudos sobre o espaço urbano para a elaboração de um plano de arborização que busque valorizar os aspectos paisagísticos e ecológicos, priorizando o uso de espécies nativas com 
potencialidade para esse tipo de uso. Em virtude disso, é de grande importância que as cidades, mesmo consideradas pequenas, como é o caso da cidade estudada, tenham um plano de arborização urbana. Isso porque independentemente do porte da cidade, é muito mais fácil realizar o planejamento e implantação, do que ações de caráter de remediação, à medida que tenta se encaixar dentro das condições já existentes no local e solucionar problemas de toda ordem, dessa forma o planejamento é a melhor ferramenta (WOLCH; BYRNE; NEWELL, 2014).

Considerando o elevado crescimento desordenado nas cidades, a falta de políticas públicas aplicáveis, além de todos os problemas, como por exemplo, geração exacerbada de resíduos e contaminação dos recursos naturais - solo e água, é necessário que seja avaliada as condições da arborização municipal e estabelecido um planejamento para melhor gestão desses recursos (CABRAL, 2013).

Diante da importância da discussão e análise do papel da arborização urbana para um melhor aproveitamento dos espaços não edificados das cidades, este estudo objetivou analisar qualitativamente e quantitativamente a arborização urbana do município de Ouro Verde do Oeste/PR por meio da identificação das espécies vegetais arbóreas plantadas nas vias públicas (passeios públicos, canteiros centrais e faixas de acompanhamento viário) e áreas verdes públicas, e também avaliar a origem das espécies (nativas ou exóticas), condições fitossanitárias e os conflitos observados com estruturas urbanas (rede elétrica, calçadas, paredes/muros, etc.).

\section{MATERIAL E MÉTODOS}

O presente estudo foi realizado no município de Ouro Verde do Oeste, oeste do estado do Paraná, localizado nas coordenadas $24^{\circ} 42^{\prime}$ de latitude sul e $53^{\circ} 46^{\prime}$ de longitude oeste, com altitude de 494 metros acima do nível do mar, e uma área territorial de $293,043 \mathrm{~km}^{2}$. O clima é temperado úmido (Cfa) (PEEL et al., 2007), com temperatura média anual de $21,4^{\circ} \mathrm{C}$, e o regime pluviométrico varia de 1600 a $2000 \mathrm{~mm}^{2} \mathrm{ano}^{-1}$. A vegetação originária da cidade está inserida no predomínio da mata atlântica - Floresta Estacional Semidecidual, atualmente, quase extinta (UHLEIN et al., 2010). De acordo com IBGE - Instituto Brasileiro de Geografia e Estatística (2010), o munícipio é formado por 5.692 habitantes, sendo que 4.039 habitantes residem na zona urbana e 1.653 na zona rural, apresentando uma densidade demográfica de 19,42 habitantes $\left(\mathrm{km}^{2}\right)^{-1}$.

Foram inventariadas todas as espécies arbóreas vivas com CAP (circunferência a 
altura do peito) mínimo $\geq 10 \mathrm{~cm}$ existentes nas vias e áreas públicas da área urbana utilizando uma régua altimétrica de $1,30 \mathrm{~m}$ e uma fita métrica. A altura total de cada indivíduo também foi calculada com o auxílio de um clinômetro.

Como quesito de avaliação de área total de sombra também foram mensurados o diâmetro de sombra de cada indivíduo, por meio da projeção da copa, para tal, com auxílio de uma trena de 50 metros, mediu-se a distância entre as extremidades da copa de forma paralela a via pública.

As espécies foram identificadas in loco com o auxílio de bibliografia especializada e seguiram a classificação das famílias botânicas. Quanto à origem fitogeográfica das espécies, consideraram-se nativas aquelas originárias de formações vegetais ocorrentes no Brasil, já as espécies que ocorrem em outros ecossistemas diferentes dos que aparecem em território brasileiro, foram consideradas exóticas.

Avaliou-se também os conflitos que os indivíduos apresentavam com estruturas urbanas, como calçadas, rede elétrica e paredes, os casos mais afetados foram fotografados e serão discutidos no decorrer deste estudo.

Calculou-se também o índice de área verde (IAV), considerando o somatório das áreas verdes dividido pelo número de habitantes da área urbana, conforme apresentado na equação 1 (HARDER; RIBEIRO; TAVARES, 2006).

$$
\text { IAVT }=\frac{\sum \text { áreas verdes totais }}{\text { Número de habitantes da área urbana }} \quad \text { Equação } 1
$$

onde:

IAVT = Índice de área verde total

$\Sigma=$ somatório

Os valores encontrados para o índice de área verde total foram confrontados com estudos já realizados e também comparados com valores estabelecidos pela Sociedade Brasileira de Arborização Urbana (1996), Instituto Brasileiro de Meio Ambiente e Recursos Naturais (IBAMA) (1995) e outros valores de referência.

\section{RESULTADOS E DISCUSSÃO}

O resultado do levantamento quantitativo, indicou a presença de 1.249 árvores, que estão distribuídas em 59 espécies nas vias (passeios públicos, canteiros centrais e faixas de acompanhamento viário) e áreas verdes (praças) do município de Ouro Verde do Oeste, sendo que $63,88 \%$ da arborização urbana do município é composta por espécies nativas, $33,72 \%$ exóticas e $2 \%$ não foram identificadas. 
Na Tabela 1 está apresentada a identificação e quantificação das árvores, seguidas da porcentagem total de cada espécie e a respectiva classificação - espécie nativa ou exótica.

Tabela 1. Apresentação das espécies encontradas na avaliação da arborização urbana de Ouro Verde do Oeste, PR

Table 1. Presentation of the species found in the evaluation of urban forestry in Ouro Verde do Oeste, PR

\begin{tabular}{|c|c|c|c|c|c|}
\hline ESPÉCIE & NOME POPULAR & FAMÍLIA & $\mathbf{N}$ & Fr (\%) & ORIGEM \\
\hline Persea americana (Mill.) & Abacateiro & Lauraceae & 7 & 0,56 & Exótica \\
\hline Eriobotrya japonica (Thunb.) Lindl. & Ameixeira-amarela & Rosaceae & 13 & 1,04 & Exótica \\
\hline Acer saccharum (J.) & Ácer-prata & Sapindaceae & 2 & 0,16 & Exótica \\
\hline Morus nigra (L.) & Amoreira & Moraceae & 8 & 0,64 & Exótica \\
\hline Psidium cattleianum (Sabine) & Araçazeiro & Myrtaceae & 2 & 0,16 & Nativa \\
\hline Annona neosalicifolia (H. Rainer) & Araticum & Annonaceae & 2 & 0,16 & Exótica \\
\hline Schinus molle (L.) & Aroeira & Anacardiaceae & 1 & 0,08 & Nativa \\
\hline Cordia ecalyculata (Vell.) & Café-de-bugre & Boraginaceae & 1 & 0,08 & Nativa \\
\hline Cassia ferruginea (Schrad.) & Canafistula & Fabaceae & 2 & 0,16 & Nativa \\
\hline Diospyros kaki (L.f.) & Caquizeiro & Ebenaceae & 1 & 0,08 & Exótica \\
\hline Toona ciliata (M. Roem.) & Cedro-australiano & Meliaceae & 5 & 0,40 & Exótica \\
\hline Cedrela fissilis (Vell.) & Cedro & Meliaceae & 1 & 0,08 & Exótica \\
\hline Eugenia involucrata (DC.) & Cerejeira & Myrtaceae & 1 & 0,08 & Nativa \\
\hline Salix babylonica (L.) & Chorão & Salicaceae & 76 & 6,08 & Exótica \\
\hline Melia azedarach (L.) & Cinamomo & Meliaceae & 10 & 0,80 & Exótica \\
\hline Cupressus macrocarpa $(\mathrm{H})$. & Cipreste & Cupressaceae & 29 & 2,33 & Exótica \\
\hline Lagerstroemia indica (L.) & Extremosa & Lythraceae & 31 & 2,48 & Exótica \\
\hline Cinnamomum burmanni (N. \& T.) & Falsa-canela & Lauraceae & 19 & 1,52 & Exótica \\
\hline Ficus benjamina (L.) & Ficus & Moraceae & 18 & 1,44 & Exótica \\
\hline Ficus auriculata (L.) & Figueira-de-jardim & Moraceae & 4 & 0,32 & Exótica \\
\hline Delonix regia (Bojer ex Hook.) Raf. & Flamboyant & Fabaceae & 29 & 2,32 & Exótica \\
\hline Psidium Guajava (L.) & Goiabeira & Myrtaceae & 17 & 1,36 & Nativa \\
\hline Campomanesia xanthocarpa (Mart.) O.Berg & Guavirova & Myrtaceae & 1 & 0,08 & Nativa \\
\hline Inga macrophylla (Humb. \& Bonpl. Ex Willd.) & Ingazeiro & Fabaceae & 1 & 0,08 & Nativa \\
\hline Handroanthus cristatus (A.H.Gentry) & Ipê-amarelo & Bignoniaceae & 18 & 1,44 & Nativa \\
\hline Handroanthus impetiginosus (Mart. Ex DC.) Mattos & Ipê-rosa & Bignoniaceae & 9 & 0,72 & Nativa \\
\hline Tabebuia roseoalba (Ridl.) Sandwith & Ipê-branco & Bignoniaceae & 1 & 0,08 & Nativa \\
\hline Tabebuia Impetiginosa (Mart. Ex DC.) Standl. & Ipê-roxo & Bignoniaceae & 12 & 0,96 & Nativa \\
\hline Myrciaria cauliflora (Mart.) O. Berg & Jabutibeira & Myrtaceae & 1 & 0,08 & Nativa \\
\hline Artocarpus heterophyllus Lam. & Jaqueira & Moraceae & 1 & 0,08 & Exótica \\
\hline Solanum paniculatum (L.) & Jurubeba & Solanaceae & 1 & 0,08 & Nativa \\
\hline Leucaena leucocephala (Lam.) de Wit & Leucena & Fabaceae & 1 & 0,08 & Exótica \\
\hline Ligustrum Lucidum (W.T.Aiton) & Ligustro & Oleaceae & 107 & 8,57 & Exótica \\
\hline Citrus $x$ limon (L.) Osbeck & Limoeiro & Rutaceae & 5 & 0,40 & Exótica \\
\hline Michelia champaca (L.) & Magnólia-amarela & Magnóliaceae & 1 & 0,08 & Exótica \\
\hline Carica papaya (L.) & Mamoeiro & Caricaceae & 6 & 0,48 & Exótica \\
\hline Tibouchina mutabilis (Vell.) Cogn. & Manacá-da-serra & Melastomataceae & 1 & 0,08 & Nativa \\
\hline Mangifera indica (L.) & Mangueira & Anacardiaceae & 39 & 3,14 & Exótica \\
\hline Melauleuca armillaris (S.M.) & Melauleuca & Myrtaceae & 1 & 0,08 & Exótica \\
\hline Erythrina mulungu (Mart.) & Mulungu & Fabaceae & 30 & 2,40 & Nativa \\
\hline Chorisia speciosa (A.St.-Hil.) & Paineira & Malvaceae & 1 & 0,08 & Nativa \\
\hline Bauhinia forficata (Link) & Pata-de-vaca & Fabaceae & 11 & 0,88 & Nativa \\
\hline Piptadenia gonoacantha (Mart.) J.F.Macbr. & Pau-jacaré & Fabaceae & 2 & 0,16 & Nativa \\
\hline Porcelia macrocarpa (Warm.) R.E.Fr. & Pente-de-macaco & Annonaceae & 1 & 0,08 & Nativa \\
\hline Aspidosperma polyneuron (M art. \& Zucc.) & Peroba & Apocynaceae & 1 & 0,08 & Nativa \\
\hline Prunus persica (L.) Batsch & Pessegueiro & Rosaceae & 4 & 0,32 & Exótica \\
\hline Xylopia amazonica (R.E. Fr.) & Pindaíba & Annonaceae & 1 & 0,08 & Nativa \\
\hline Duranta erecta aurea (L.) & Pingo-de-ouro & Verbenaceae & 1 & 0,08 & Nativa \\
\hline Eugenia uniflora (L.) & Pitangueira & Myrtaceae & 11 & 0,88 & Nativa \\
\hline Bougainvillea glabra (Choisy.) & Primavera & Nyctaginaceae & 1 & 0,08 & Nativa \\
\hline Tibouchina granulosa (Desr.) Cogn. & Quaresmeira & Melastomataceae & 1 & 0,08 & Exótica \\
\hline Lecythis pisonis (Cambess.) & Sapucaia & Lecythidaceae & 45 & 3,60 & Nativa \\
\hline Caesalpinia peltophoroides (Benth.) & Sibipiruna & Fabaceae & 614 & 49,16 & Nativa \\
\hline Spondias purpurea (L.) & Seriguela & Anacardiaceae & 5 & 0,40 & Nativa \\
\hline Tipuana tipu (Benth.) Kuntze & Tipuana & Fabaceae & 2 & 0,16 & Nativa \\
\hline \multirow[t]{2}{*}{ Bixa Orellana (L.) } & Urucum & Bixaceae & 3 & 0,24 & Nativa \\
\hline & Não identificado & & 30 & 2,40 & \\
\hline TOTAL DE INDIVÍDUOS & & & 1249 & 100 & \\
\hline
\end{tabular}

Legenda: $\mathrm{N}=$ número de indivíduos, $\mathrm{Fr}=$ frequência, $\mathrm{O}=$ origem

Key: $\mathrm{N}=$ individuals number, $\mathrm{Fr}=$ relative frequency, $\mathrm{O}=$ origin 
Dentre as 1.249 árvores catalogadas pode-se verificar que algumas espécies apresentaram maior frequência, destacando-se duas espécies a Caesalpinia peltophoroides G. P. Lewis (sibipiruna) com 614 indivíduos, seguida da espécie Ligustrum Lucidum W. T. Aiton (ligustro) com 107 indivíduos. As duas espécies que apresentam maior abundância são espécies de porte grande, apresentando pontos positivos (área de sombra) e negativos (ocorrência de conflitos com a rede elétrica e calçadas).

De acordo com Kenney, Van Wassenaer e Satel (2011), em um adequado planejamento da arborização, cada espécie não deve ultrapassar de 10 a $15 \%$ do total de indivíduos arbóreos na área urbana. Se confrontarmos esses valores com os resultados obtidos no presente estudo é possível observar que o município de Ouro Verde do Oeste não segue essas recomendações, pois Caesalpinia peltophoroides representa sozinha $49,16 \%$ do total de indivíduos arbóreos da área urbana.

Segundo Souza et al. (2011), o predomínio de poucas espécies por unidade de área também promove a homogeneidade florística, que se torna um grande risco para a proliferação de pragas e doenças na vegetação urbana. Além disso, quando analisados aspectos como, sujeira, conflito com redes elétricas e calçadas, entre outros, as espécies que apresentam maior queixa pelos moradores são aquelas de grande porte, entre elas a Caesalpinia peltophoroides. Em contrapartida, as árvores que apareceram em maior abundância são as que proporcionam uma maior área de sombra, além de fornecerem maior ventilação e melhor controle de temperatura.

É válido salientar que muitas das árvores encontradas no município foram introduzidas na paisagem urbana pelos próprios moradores há muitos anos, sem nenhum planejamento prévio ou até mesmo sem conhecimento das características das espécies, ou qual o local mais adequado para cada uma. Outra característica encontrada são as podas irregulares, que assim como o plantio de mudas, na maioria dos casos, são realizadas pelos moradores, ocorrendo podas irregulares e também podas drásticas.

A relação estabelecida entre a população e o manejo das árvores em ambiente urbano, como por exemplo a poda das árvores, é uma questão cultural bastante enraizada na população urbana, que acredita estar agindo de forma correta, entretanto, na realização das podas deve-se dar atenção a morfologia da árvore, pois qualquer tipo de poda é uma agressão ao indivíduo e deve ocorrer de forma cuidadosa (LUNDGREN et al., 2014).

O fato de maior ocorrência de árvores de espécies nativas é positivo, tendo em vista a importância da presença de espécies nativas, porém é necessário que seja avaliada capacidade de adaptação, sobrevivência e desenvolvimento no local do plantio, características como porte, tipo de copa, folhas, flores, ausência de frutos, hábito de 
crescimento das raízes, ausência de princípios tóxicos, adaptabilidade climática, resistência a pragas e doenças, tolerância a poluentes e a baixas condições de aeração do solo (HOPPEN et al., 2014).

Em relação às espécies exóticas, a que apresentou maior frequência foi o Ligustrum lucidum, árvore de porte grande, apresentando um sistema radicular agressivo e forte suficiente para arrebentar calçadas, podendo gerar sérios danos às vias públicas impedindo a passagem de pedestres, além disso, a sua utilização não é recomendada para arborização urbana por não contribuir para a biodiversidade do local (KRAMER; KRUPEK, 2012). Gonçalves, Coral e Siqueira (2017) mencionam que Ligustrum Lucidum foi avaliada como a espécie mais frequente em áreas verdes e espaços públicos do centro do município de lbitinga no estado de São Paulo. Segundo os mesmos autores, essa espécie é amplamente utilizada na arborização urbana, sobretudo nas regiões Sul e Sudeste do Brasil, onde é possível encontrá-la com facilidade.

Diante de tais resultados é necessário que se tome alguns cuidados com as manutenções dessas espécies, um exemplo são as podas realizadas de maneira inadequada que podem causar problemas fitossanitários ou mesmo ocasionar a morte da árvore. Além deste fator, outro fator preocupante é que as duas espécies que foram identificadas com maior frequência são de grande porte, podendo causar diversos conflitos. Observou-se no decorrer do trabalho alguns conflitos com estruturas urbanas como por exemplo: calçada, calçada/rede elétrica, rede elétrica, rede elétrica/poda, rede elétrica/raiz exposta.

Embora tenham sido observados diferentes situações de conflitos (Figura 1), mais de $65 \%$ não apresentaram conflito (Figura 2), sendo de maior ocorrência o conflito com a rede elétrica. 

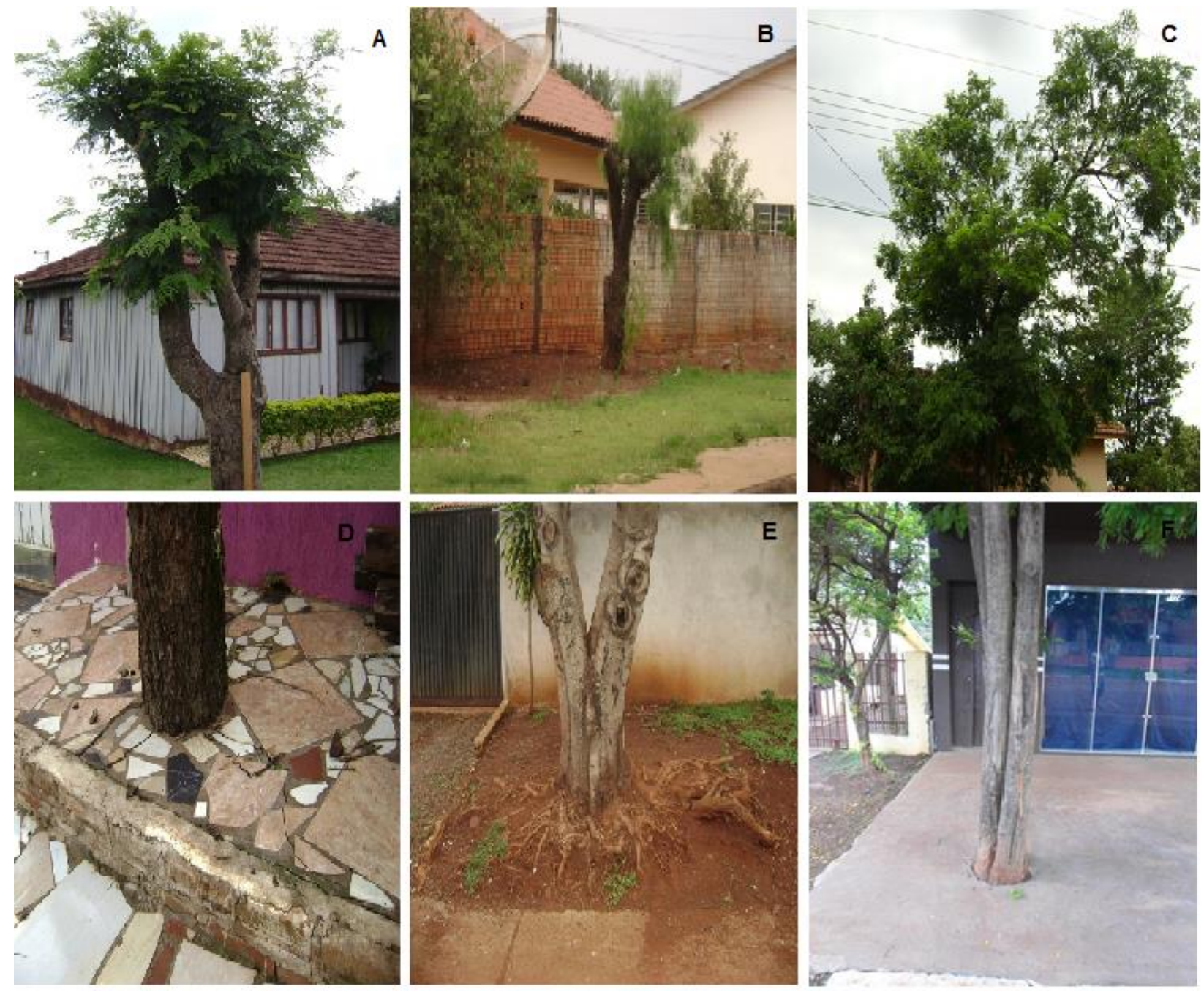

Figura 1. Imagens A e B) Podas drásticas realizadas pela população sob a arborização urbana no município de Ouro Verde do Oeste/PR. Imagem C) Conflito observado entre rede elétrica/telefonia e arborização urbana no município de Ouro Verde do Oeste/PR. Imagens D, E e F) Conflitos observados entre calçadas/raízes expostas e arborização urbana no município de Ouro Verde do Oeste/PR.

Figure 1. Images A and B) Drastic pruning made by the population on the urban trees in the municipality of Ouro Verde do Oeste / PR. Image C) Conflict observed between electricity/telephone network and urban afforestation in the municipality of Ouro Verde do Oeste / PR. Images D, $\mathrm{E}$ and F) Conflicts observed between sidewalks/exposed roots and urban afforestation in the municipality of Ouro Verde do Oeste / PR.

A altura média das árvores catalogadas foi de 7,67 m, sendo que o maior indivíduo encontrado pertencente à espécie Cinnamomum burmanni (Lauraceae), com uma altura de 23,25 m, conhecido popularmente por canela ou falsa-canela, que é uma árvore exótica, que pode atingir grandes alturas podendo trazer sérios problemas à rede elétrica (Tabela 2). 


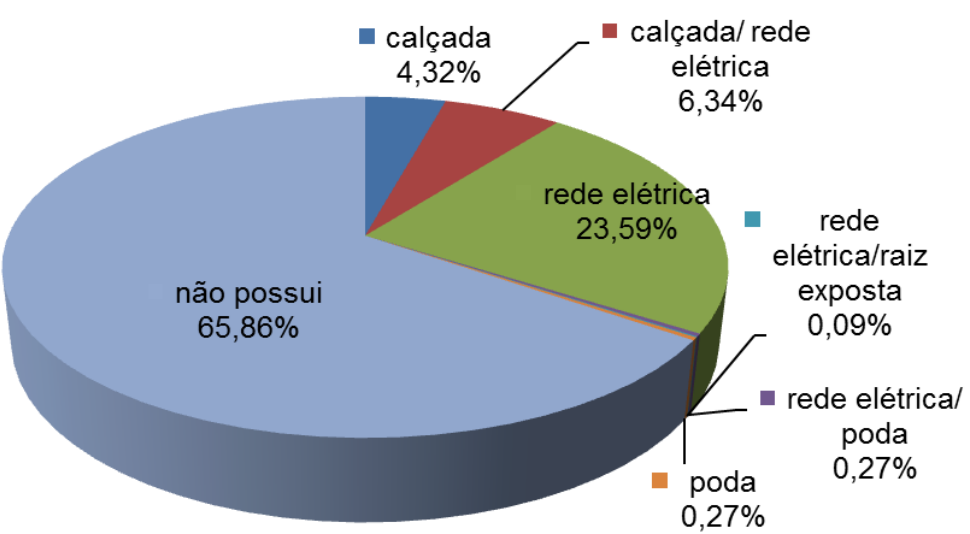

Figura 2. Percentual de conflitos encontrados entre arborização e estruturas urbanas no município de Ouro Verde do Oeste/PR

Figure 2. Percentage of conflicts found between afforestation and urban structures in the municipality of Ouro Verde do Oeste / PR

Em relação ao CAP, conforme apresentado na Tabela 2, é possível observar CAP máximo de $325 \mathrm{~cm}$. Por meio deste resultado é possível verificar que existem algumas espécies que são mais antigas e mais grossas, como exemplo as espécies de Toona ciliata M. Roem. (cedro) e Caesalpinia peltophoroides G. P. Lewis (sibipiruna). Assim como as que apresentaram um CAP mínimo $(10,8 \mathrm{~cm})$, são espécies jovens, dentre elas destacam-se sete copas, falsa canela, entre outras.

Tabela 2. Circunferência altura do peito (CAP) e altura das árvores catalogadas no município de Ouro Verde do Oeste/PR.

Table 2. Chest height circumference $(\mathrm{CHC})$ and height trees cataloged in the municipality of Ouro Verde do Oeste / PR.

\begin{tabular}{cccc}
\hline & Mínima & Média & Máxima \\
\hline Diâmetro $(\mathrm{cm})$ & 10,80 & 78,23 & 325,00 \\
\hline Altura $(\mathrm{m})$ & 1,93 & 7,67 & 23,25 \\
\hline
\end{tabular}

Em alguns locais da cidade, por serem considerados novos loteamentos, é possível visualizar poucos indivíduos arbóreos, o que permite que a gestão pública se beneficie e realize um planejamento da arborização, pois a população ainda não se estabeleceu e o planejamento evitaria problemas futuros.

Das 47 ruas que foram analisadas, observa-se que apenas 10 ruas concentram cerca de 59\% de toda arborização; as localizações com maior número de indivíduos são as principais ruas de acesso do município (avenidas) e a praça central, locais onde a concentração de pessoas é maior. Contudo, é necessário que a arborização de determinado município seja uniforme, isto é, que os indivíduos arbóreos estejam devidamente distribuídos 
em todo ambiente urbano, pois dessa forma, problemas de locais com elevado número de indivíduos e outros com quantidade reduzida seriam evitados (LABAKI et al., 2011)

A partir dos cálculos de sombra realizados, a partir das medidas das copas das árvores, o valor encontrado para as áreas de sombra foi de $24.284,79 \mathrm{~m}^{2}$. Portanto, considerando que o número de habitantes urbanos é de 4.039, o índice de área verde (IAV) total encontrado foi igual a $6,01 \mathrm{~m}^{2}$ por habitante. O Quadro 1 apresenta valores de IAV indicados por referências no Brasil e no mundo.

\begin{tabular}{|c|c|}
\hline INSTITUIÇÃO & VALOR INDICADO \\
\hline Sociedade Brasileira de Arborização Urbana (1996) & $15 \mathrm{~m}^{2}$ por habitante \\
\hline Resolução conjunta IBAMA/FATMA 001/95 & $8 \mathrm{~m}^{2}$ por habitante \\
\hline Estocolmo - Referência mundial (MENEZES, 2016) & $86 \mathrm{~m}^{2}$ por habitante \\
\hline Ouro Verde do Oeste & $6,01 \mathrm{~m}^{2}$ por habitante \\
\hline
\end{tabular}

Quadro 1. Valores indicados por diferentes órgãos/referências para o índice de área verde nas cidades comparados ao valor encontrado em Ouro Verde do Oeste/PR

Box 1. Values indicated by different organs/references for the green area index in cities compared to the value found in Ouro Verde do Oeste / PR

Como pode-se observar o IAV encontrado para o município de Ouro Verde do Oeste está abaixo do indicado por órgãos de referência, entretanto quando comparados a outros estudos realizados, o índice encontrado para o munícipio apresenta-se mais elevado. De acordo com Pires et al. (2010), o IAV encontrado para o munícipio de Goiandira/GO, foi de 1,29 $\mathrm{m}^{2}$ por habitante. O município de Goiandira possui aproximadamente o mesmo número de habitantes do município em estudo, e, portanto, o munícipio de Ouro Verde do Oeste apresenta um valor de área verde por habitante bem superior à Goiandira, propiciando aos seus munícipes uma melhor qualidade de vida. Contudo, Ouro Verde do Oeste/PR ainda apresenta IAV abaixo do recomendado pela literatura.

De acordo com Pirovani et al. (2012) para o município de Cachoeira do Itapemirim/ES o IAV encontrado foi de aproximadamente 35,04 $\mathrm{m}^{2}$ por habitante, o que quando comparado a Ouro Verde do Oeste, apresenta uma variação considerável. Contudo, Santos et al. (2014) apontam que de um modo geral, os municípios brasileiros apresentam IAV bastante reduzido, e quando atendem as taxas consideradas ótimas pela literatura geralmente levam em consideração áreas centrais dos municípios.

A área verde mínima necessária para que o município de Ouro Verde do Oeste atingisse o indicado pela Sociedade Brasileira de Arborização Urbana é de $60.585,00 \mathrm{~m}^{2}$, o que se apresenta como sendo superior ao dobro de área existente atualmente. Dessa forma, o valor encontrado $\left(6,01 \mathrm{~m}^{2}\right)$ apresenta-se como critério que pode ser melhorado com o auxílio de um planejamento arbóreo, melhorando, consequentemente, a qualidade de vida da população ouroverdense. 


\section{CONCLUSÕES}

O número de espécies nativas é elevado o que soa de forma positiva, tendo em vista que estas espécies são as mais indicadas na composição da arborização urbana, entretanto, a população, por questões culturais, faz a manutenção e o plantio de forma que julga correta, propiciando condições nem sempre favoráveis aos recursos vegetais arbóreos.

Com a realização desse estudo pode-se considerar que as condições da arborização urbana de Ouro Verde do Oeste, ao que diz respeito ao índice de área verde, encontram-se abaixo quando comparado ao estabelecido por órgãos nacionais e internacionais de representatividade na área, entretanto, quando comparado a outros municípios brasileiros, Ouro Verde do Oeste enquadra-se como razoável.

Sugere-se que o governo municipal tenha melhor controle sobre a arborização das vias públicas, por meio da elaboração de um plano de arborização, ferramenta que auxiliaria muito na readequação da arborização bem como sua adequada manutenção.

\section{REFERÊNCIAS}

BARGOS, D. C.; MATIAS, L. F. Mapeamento e análise de áreas verdes urbanas em Paulínia (SP): Estudo com a aplicação de geotecnologias. Sociedade \& Natureza, Uberlândia-MG, v.24, n. 1, p. 143-156, 2012.

CABRAL, I. D. Arborização Urbana: problemas e benefícios. Revista Especialize On-line, Goiânia-GO, v. 1, n. 6, p. 1-15, 2013.

GONÇALVES, W. B.; CORAL, D. J.; SIQUEIRA, M. V. B. M. Caracterização da arborização urbana no bairro centro do município de lbitinga/SP. Revista da Sociedade Brasileira de Arborização Urbana, Piracicaba-SP, v. 12, n. 3, p. 66-79, 2017.

HARDER, I. C. F.; RIBEIRO, R. C. S.; TAVARES, A. R. Green área and vegetation cover indexes for commons in the city of Vinhedo, SP. Revista Árvore, Viçosa-MG, v. 30, n. 2, p. $277-282,2006$.

HOPPEN, M. I.; DIVENSI, H. F.; RIBEIRO, R. F.; CAXAMBÚ, M. G. Espécies Exóticas na arborização de vias públicas no município de Farol, PR, Brasil. Revista da Sociedade Brasileira de Arborização Urbana, Piracicaba - SP, v. 9, n. 3, p. 173 - 186, 2014.

IBAMA/FATMA. Instituto Brasileiro de Meio Ambiente e Recursos Naturais e Órgão Ambiental Estadual de Santa Catarina. Resolução conjunta IBAMA/FATMA 001/95, 1995. Disponível em: <www.ipef.br/legislacao/bdlegislacao/arquivos/306.rtf>. Acesso em: 14 mar. 2018.

IBGE. Instituto Brasileiro de Geografia e Estatística. Censo 2010. Disponível em:<http://www.censo2010.ibge.gov.br/resultados>. Acesso em: 10 fev. 2017. 
KENNEY, W. A.; VAN WASSENAER, P. J. E.; SATEL, A. L. Criteria and indicator for strategic urban forest planning and management. Arboriculture \& Urban Forestry, Kenney, v. 37, n. 3, p. 108-117, 2011.

KRAMER J. A.; KRUPEK R. A. Caracterização florística e ecológica da arborização de praças públicas do município de Guarapuava, PR. Revista Árvore, Viçosa-MG, v.36, n.4, p.647-658, 2012.

LABAKI, L. C.; SANTOS, R. F. S.; BARTHOLOMEI, B.; LOTUFO, C.; ABREU, L. V. Vegetação e conforto térmico em espações urbanos abertos. Fórum Patrimônio, Belo Horizonte-MG, v. 4, n. 1, 2011.

LUNDGREN, W. J. C.; SILVA, L. F. da; SILVA, M. A.; PEDROSA, P. E. R. Influência da orientação habitacional sobre o número de árvores existentes nas ruas de Serra Talhada/PE.

Revista da Sociedade Brasileira de Arborização Urbana, Piracicaba-SP, v. 9, p. 1-17, 2014.

MARTINI, A.; BIONDI, D. Microclima e conforto térmico de um fragmento de floresta urbana em Curitiba, PR. Floram - Revista Floresta e Ambiente, Rio de Janeiro-RJ, v. 22, p. 182193, 2015.

MCPHERSON, E. G.; SIMPSON, J. R.; XIAO, Q.; WU, C. Million trees Los Angeles canopy cover and benefit assessment. Landscape and Urban Planning, Nova York, v. 99, n. 1, p. 40-50, 2011.

MENEZES, F. Z. Uma árvore por habitante, a recomendação mínima da OMS para as cidades. Jornal Gazeta do Povo - O futuro das cidades. 2016. Disponível em: <https://www.gazetadopovo.com.br/vida-e-cidadania/futuro-das-cidades/uma-arvore-porhabitante-a-recomendacao-minima-da-oms-para-as-cidades-622ch9afm4rimh3ol1 w9j8ikn/>. Acesso em: 17 dez. 2018.

ORGANIZAÇÃO DAS NAÇÕES UNIDAS - ONU. Department of Economic and Social Affairs, Population Division. World Urbanization Prospects: The 2014 Revision. New York, 2015. Disponível em: <https://esa.un.org/unpd/wup/Publications/Files/WUP2014-Report.pdf>. Acesso em: 27 ago. 2017.

PEEL, M. C.; FINLAYSON, B. L.; MCMAHON, T. A. Update world map of the Köppen-Geiger climate classification. Hydrol. Earth Syst. Sci, Londres, v. 11, p. 1633-1644, 2007.

PIRES, N. A. M. T.; MELO, M. S.; OLIVEIRA, D. E.; SANTOS, S. X. A arborização urbana do município de Goiandira/GO - caracterização quali-quantitativa e propostas de manejo. Revista da Sociedade Brasileira de Arborização Urbana, Piracicaba-SP, v. 5, n. 3, p. 185205, 2010.

PIROVANI, D. B.; SILVA A. G.; OLIVEIRA, O. M.; CALIMAN, J. P. Áreas Verdes Urbanas de Cachoeiro de Itapemirim-ES. Enciclopédia BIOSFERA, Goiânia, v.8, n.15; p. 171, 2012.

PORTNEY, K. E. Taking sustainable cities seriously: economic development, the environment, and quality of life in American cities. $2^{\underline{a}}$ ed. The MIT press/Londres/Inglaterra, 2013. 
SANTOS, Z. R.; CARNEIRO, D. C.; MALISKI, L. F.; GONCALVES, N. G. T.; CARVALHO, S. M. Análise da arborização urbana da área central de Ponta Grossa - PR. Revista Perspectiva Geográfica, Cascavel-PR, v. 9, p. 1-16, 2014.

SOCIEDADE BRASILEIRA DE ARBORIZAÇÃO URBANA - SBAU. Carta a Londrina e Ibiporã, Boletim Informativo, Piracicaba-SP, v. 3, n. 5, p. 3, 1996.

SOUZA, A. L.; FERREIRA, R. A.; MELO, A. A. de; PLÁCIDO, D. da R.; SANTOS, C. Z. A. dos; GRAÇA, D. A. S. da; ALMEIRA JÚNIOR, P. P. de; BARETTO, S. S. B. B; DANTAS, J. D. M.; PAULA, J. W. A. de; SILVA, T. L. da; GOMES, L. P. S. Diagnóstico Quantitativo e Qualitativo Da Arborização das Praças de Aracaju, SE. Revista Árvore, Viçosa-MG, v.35, n.6, p.12531263, 2011.

UHLEIN, A.; CASTAGNARA, D. D.; PERINI, L. J.; FEIDEN, A., SILVA, N. L. S. da.; SILVA, P. C. S. da.; ZONIN, W. J. Estudo da fragmentação florestal na microbacia hidrográfica do córrego Poço Grande - Município de Ouro Verde do Oeste - PR. Revista Varia Scientia Agrárias, Cascavel-PR, v. 01, n. 01, p. 87-99, 2010.

WOLCH, J. R.; BYRNE, J.; NEWELL, J. P. Urban green apace, public health, and environmental justice: The challenge of making cities 'just green enough'. Landscape and Urban Planning, Nova York, v. 125, p. 234-244, 2014. 